\title{
SISTEMAS AGROFLORESTAIS NO MUNICÍPIO DE PARAGOMINAS, PARÁ.
}

\author{
A. O. DOS SANTOS ${ }^{1}$ e R. C. R. DA SILVA ${ }^{2}$ \\ Instituto Federal de Educação, Ciência e Tecnologia do Pará \\ abimaelufra@gmail.com ${ }^{1}$
}

Submetido 13/02/2020 - Aceito 15/04/2020

DOI: $10.15628 /$ holos.2020.9548

\section{RESUMO}

Este trabalho teve como objetivo identificar e analisar os sistemas agroflorestais em Paragominas, gerando informações para subsidiar ações públicas de implantação de novos arranjos de SAF's no referido município. Foi realizado através de pesquisa de campo com coleta de dados e aplicação de questionário semiestruturado, com questões envolvendo aspectos socioeconômicos, fundiários, uso e ocupação do solo, produção e comercialização, políticas públicas e controle fitossanitário. Foram identificadas 21 comunidades com sistemas agroflorestais. Foi aferido $18 \%$ de áreas com SAF's no município, pequenas comunidades em sua maioria. Quanto à regularização fundiária, apenas $24 \%$ são titulares contra $37 \%$ de posseiros. Em relação ao controle fitossanitário, $45 \%$ dizem ter usado algum tipo de produto químico, com destaque para os herbicidas.
$58 \%$ possuem apenas o ensino fundamental incompleto enquanto $2 \%$ apresentam ensino superior. $67 \%$ participam de alguma organização social. Sobre a renda familiar, $75 \%$ sobrevivem com até um salário mínimo. Foram identificadas 34 culturas prioritárias nos SAF's, com destaque para açaí, cupuaçu, abacaxi, melão, canade-açúcar, melancia, castanha do Pará, mogno, andiroba e ipê. $48 \%$ dos participantes fazem algum tipo de beneficiamento, com ênfase para farinha, $66 \%$, e polpa de fruta, $26 \%$. Quanto ao destino dos produtos, 33\% são comercializados na comunidade local e $31 \%$ vão para feiras livres na cidade. Os problemas na comercialização mais apontados foram a falta de comprador fixo, 35\%, e estradas ruins, $24 \%$. No tocante ao acesso a financiamento, $29 \%$ tiveram acesso, dos quais $56 \%$ ao Pronaf $A, 12,5 \%$ ao FNO e $12,5 \%$ a microcrédito.

PALAVRAS-CHAVE: Comunidades Rurais, Agricultura Familiar, Diagnóstico.

\section{AGROFORESTRY SYSTEMS IN THE CITY OF PARAGOMINAS, PARÁ}

\section{ABSTRACT}

This work aimed to identify and analyze the agroforestry systems in Paragominas, generating information to support public actions for the implementation of new SAF's arrangements in that municipality. It was carried out through field research with data collection and application of a semi-structured questionnaire, with questions involving socioeconomic, land tenure, land use and occupation, production and commercialization, public policies and phytosanitary control. 21 communities were identified with agroforestry systems. $18 \%$ of areas with SAF's in the municipality were measured, mostly small properties. As for land tenure regularization, only $24 \%$ are owners against $37 \%$ of squatters. Regarding phytosanitary control, $45 \%$ say they have used some type of chemical product, especially herbicides. $58 \%$ have only incomplete elementary education, while $2 \%$ have higher education. $67 \%$ participate in some social organization. Regarding family income, $75 \%$ survive on up to a minimum wage. 34 priority crops were identified in the SAF's, with emphasis on açaí, cupuaçu, pineapple, melon, sugar cane, watermelon, Brazil nuts, mahogany, andiroba and ipe. $48 \%$ of participants do some kind of processing, with an emphasis on $66 \%$ flour and $26 \%$ fruit pulp. As for the destination of the products, $33 \%$ are sold in the local community and $31 \%$ go to open markets in the city. The most pointed problems in the commercialization were lack of fixed buyer, $35 \%$ and bad roads $24 \%$. Regarding access to finance, $29 \%$ had access, of which $56 \%$ to Pronaf A, $12.5 \%$ to FNO and $12.5 \%$ to microcredit.

KEYWORDS: Rural Communities, Family Farming, Diagnosis. 


\section{INTRODUÇÃO}

A Amazônia brasileira tem sido palco de grandes discussões a respeito do avanço do desflorestamento. Em números absolutos, os estados que mais desmataram no ano de 2016 foram: Pará (3.025 km2), Mato Grosso (1.508 km2) e Rondônia (1.394 km2), compreendendo juntos $75 \%$ de todo desmatamento registrado no período (AZEVEDO, 2016).

O município de Paragominas, localizado no nordeste do Estado do Pará, apresenta um histórico que expressa muito bem essa problemática, sendo apontado, com base nos dados do PRODES/INPE 2009, divulgado pelo Instituto Nacional de Pesquisas Espaciais (INPE), como um dos municípios que mais sofreu desmatamentos no Estado, com quase $45 \%$ de sua área devastada até o ano de 2008. Porém, essa realidade foi enfrentada pelo poder público, em parceria com a sociedade civil, e, em 2008, iniciou-se uma virada nessa situação de desmatamento com a assinatura do Pacto pelo Desmatamento Zero.

Apesar do município de Paragominas ter saído da categoria de desmatador, a taxa de área verde, no final de 2011 , era de $10,3 \mathrm{~m}^{2}$ por habitante, e, em 2016 , a cidade contava com $66,45 \%$ de todo seu território com floresta nativa considerada área protegida, além de 11 mil hectares que foram reservados para a criação do Parque Ambiental Municipal de Paragominas. No entanto, são necessárias mais ações governamentais que fomentem políticas públicas para os agricultores familiares, incentivando-os a produzir de forma sustentável

Segundo Abdo et al. (2008), pelo fato de a Agricultura familiar dispor em geral de áreas reduzidas, faz-se necessário um olhar mais cuidadoso no que diz respeito à escolha do sistema de exploração, para que assim se possa garantir uma produção sustentável ao longo do tempo. Devese considerar o fato de que, via de regra, a atividade agropecuária nessas áreas é intensiva, de forma a obter rendimentos mais satisfatórios possíveis, sem desconsiderar questões como a ciclagem de nutrientes e manejo adequado do solo, visando sua conservação e a biodiversidade de espécies a serem implantadas nesse agroecossistema.

Nesse sentido, os sistemas agroflorestais são alternativas extremamente viáveis do ponto de vista econômico, social e ambiental, pois conseguem atrelar produção econômica com qualidade ambiental e desenvolvimento local dentro de sua complexa teia de produção.

Áreas com plantios agroflorestais apresentam grande potencial para o aumento da biodiversidade e contribuem para diminuir a pressão humana sobre as florestas nativas, devido à sua multifuncionalidade no nível da propriedade e da paisagem (MICCOLINS, et al., 2016). Dessa forma, essas áreas podem se tornar um refúgio para a vida animal, que tolera certo nível de distúrbio de uma dada região, podendo servir também como corredor animal para espécies mais sensíveis.

No entanto, o processo de seleção e implantação de SAFs na Amazônia tem acontecido de forma desordenada e sem a devida planificação. O desconhecimento do potencial dos recursos naturais tem sido um dos principais elementos para que tal fato ocorra. Com isso, várias zonas são ocupadas inadequadamente, implantando-se espécies em locais inaptos ao seu desenvolvimento, diminuindo a produtividade e a capacidade produtiva do solo, bem como desperdiçando recursos. Esses obstáculos demandam soluções alternativas no planejamento, implantação e monitoramento de SAFs, que sejam adequadas às características e peculiaridades da região. Assim, 
uma nova proposta metodológica precisa ser assimilada, justificando-se, portanto, a geração de um modelo de planejamento de SAFs adaptado à realidade do produtor rural, cooperando para a melhoria das condições socioeconômicas dos mesmos (OLIVEIRA, 2016).

Por isso, este trabalho teve como objetivo geral identificar e analisar os sistemas agroflorestais existentes em propriedades familiares no munícipio de Paragominas, como estratégias para ampliar ações públicas de manutenção e implantação de arranjos de SAF's no referido município. Os objetivos específicos foram: quantificar os SAF's no munícipio de Paragominas; analisar as espécies componentes e o sistema de produção dos arranjos agroflorestais existentes nas comunidades; traçar o perfil socioeconômico dos agricultores familiares das áreas com SAF em Paragominas.

\section{METODOLOGIA}

Os dados desta pesquisa foram extraídos do projeto acadêmico intitulado "Diagnóstico da Agricultura Familiar de Paragominas", aplicados por docentes e discentes do curso de mestrado profissional em desenvolvimento rural sustentável do Instituto Federal de Educação, Ciência e Tecnologia do Pará, campus Castanhal, em parceria com a prefeitura municipal de Paragominas. Assim, foram elaboradas as questões do diagnóstico geral com objetivo de atender às diversas demandas de pesquisas dos mestrandos, inclusive as referentes a quantificação e características de sistemas agroflorestais no município, base deste trabalho.

\subsection{Histórico da pesquisa e caracterização do local}

A partir do ano de 2013, o governo do estado do Pará, em parceria com municípios, sociedade organizada e iniciativa privada, iniciou o Programa Estadual Municípios Verdes, com o objetivo de fomentar a recuperação de áreas alteradas e/ ou degradadas em propriedades rurais familiares de diversas regiões do estado. Assim também foram ocorrendo as ações de implantação de Sistemas Agroflorestais - SAF's no município de Paragominas.

O município de Paragominas, situado às margens da rodovia Belém-Brasília (BR-010), a 320 quilômetros da cidade de Belém, possui uma área de 1,93 milhões de hectares (1,5\% da superfície do Pará) e abriga uma população de quase 110 mil habitantes (IBGE, 2016). Faz parte da mesorregião sudeste paraense e se limita com o Maranhão, a leste, e com cinco municípios paraenses: Ipixuna do Pará e Nova Esperança do Piriá, ao norte; Ulianópolis, Goianésia do Pará e Dom Eliseu, ao sul; e Ipixuna do Pará, a oeste (Figura 1). 


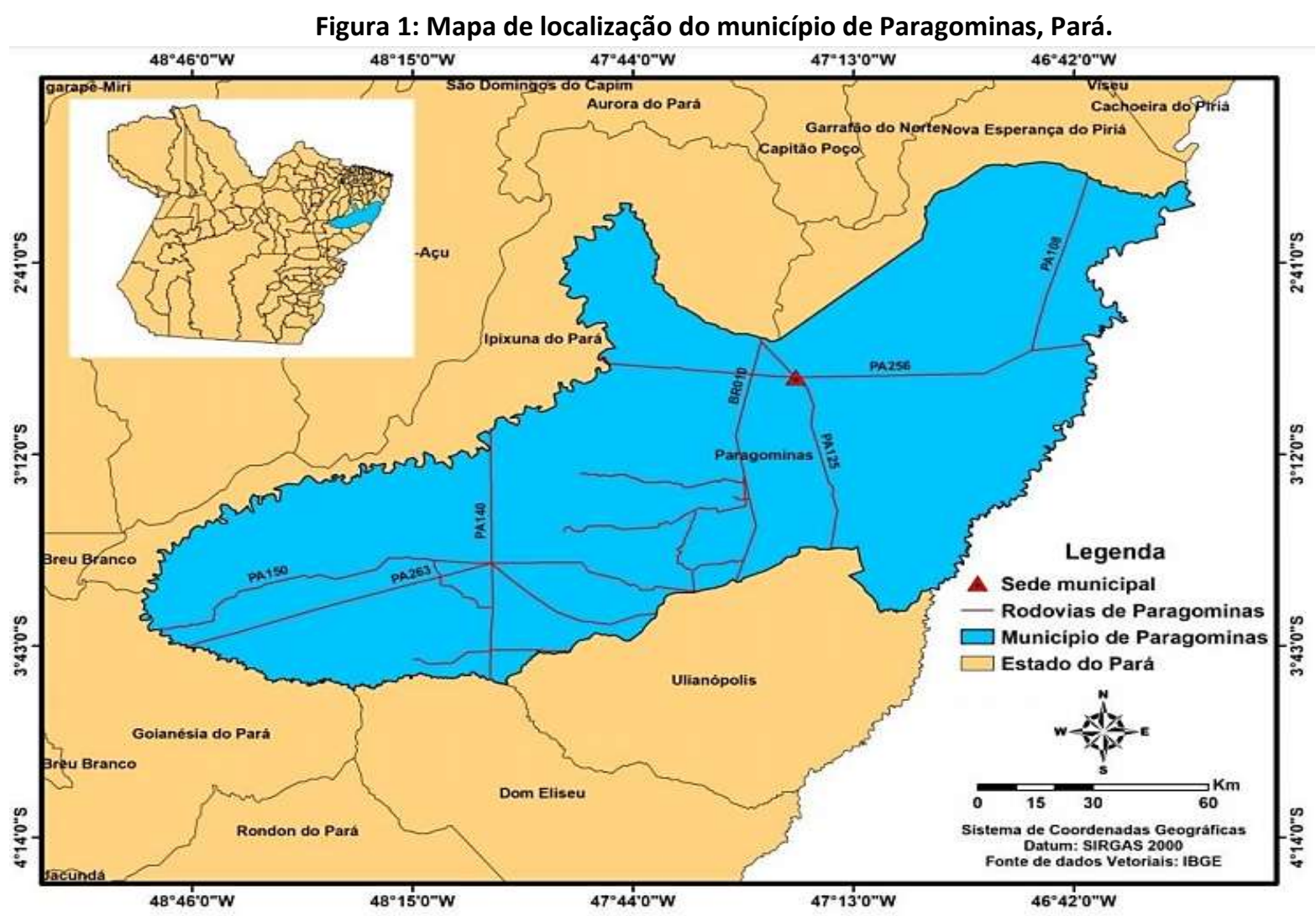

Fonte: CARVALHO et al. (2017).

Quanto ao uso e à ocupação do solo, esse município apresenta altos níveis de desmatamento ao longo de seu histórico, devido aos passivos remanescentes das atividades madeireiras, pela abertura de pastagens e pelo avanço do agronegócio, sendo fortemente representado pelo cultivo de soja e pela pecuária (INPE/PRODES, 2013).

\subsection{Diagnóstico rural participativo}

\subsubsection{Escolha das localidades}

Na primeira etapa do trabalho foi construído um mapa (Figura 2) com as representações das Comunidades Rurais cadastradas nos órgãos municipais, de forma a definir quais localidades seriam visitadas. De acordo com informações populacionais do Instituto Nacional de Reforma Agrária - INCRA, Instituto de terras do Pará - ITERPA e Instituto Brasileiro de Geografia e Estatística - IBGE, foi determinada uma amostragem de $10 \%$ do número total das comunidades rurais existentes no município para aplicar os questionários do diagnóstico.

As entrevistas foram realizadas no período de julho a setembro de 2018, em 309 propriedades rurais, de 32 localidades selecionadas pela equipe do projeto, de forma a representar todo o território do município.

Para atender aos objetivos desta pesquisa, do número total de comunidades amostradas, foram identificadas e selecionadas vinte e uma com arranjos de sistemas agroflorestais, objetivo 
desta pesquisa, que são: Água Suja; Bacaba, Cachoeira; Colônia do Uraim; Colônia Oriente; Colônia Providência; Escadinha; Faixa 1 CAIP; Faixa 3 CAIP; Faixa 5 CAIP; Faixa do Aprisco CAIP; Faixa do Tauari CAIP; Glebinha; Km 15; Mandacaru; Nazaré; Nova Jerusalém; Paragonorte; Perack; Vila da CAIP; e em duas comunidades sem identificação.

O critério de escolha individual dos entrevistados se deu com a participação dos líderes comunitários e assistencionistas da Secretaria Municipal de Agricultura de Paragominas, por conhecerem a realidade do campo e a localização dos lotes de agricultores familiares. A quantidade de famílias entrevistadas em cada comunidade se deu de acordo com o percentual estatístico confiável de $10 \%$ para cada localidade. Esses envolvidos acompanharam a equipe de campo na aplicação dos questionários.

Figura 2: Mapa representativo das comunidades de Paragominas, Pará.

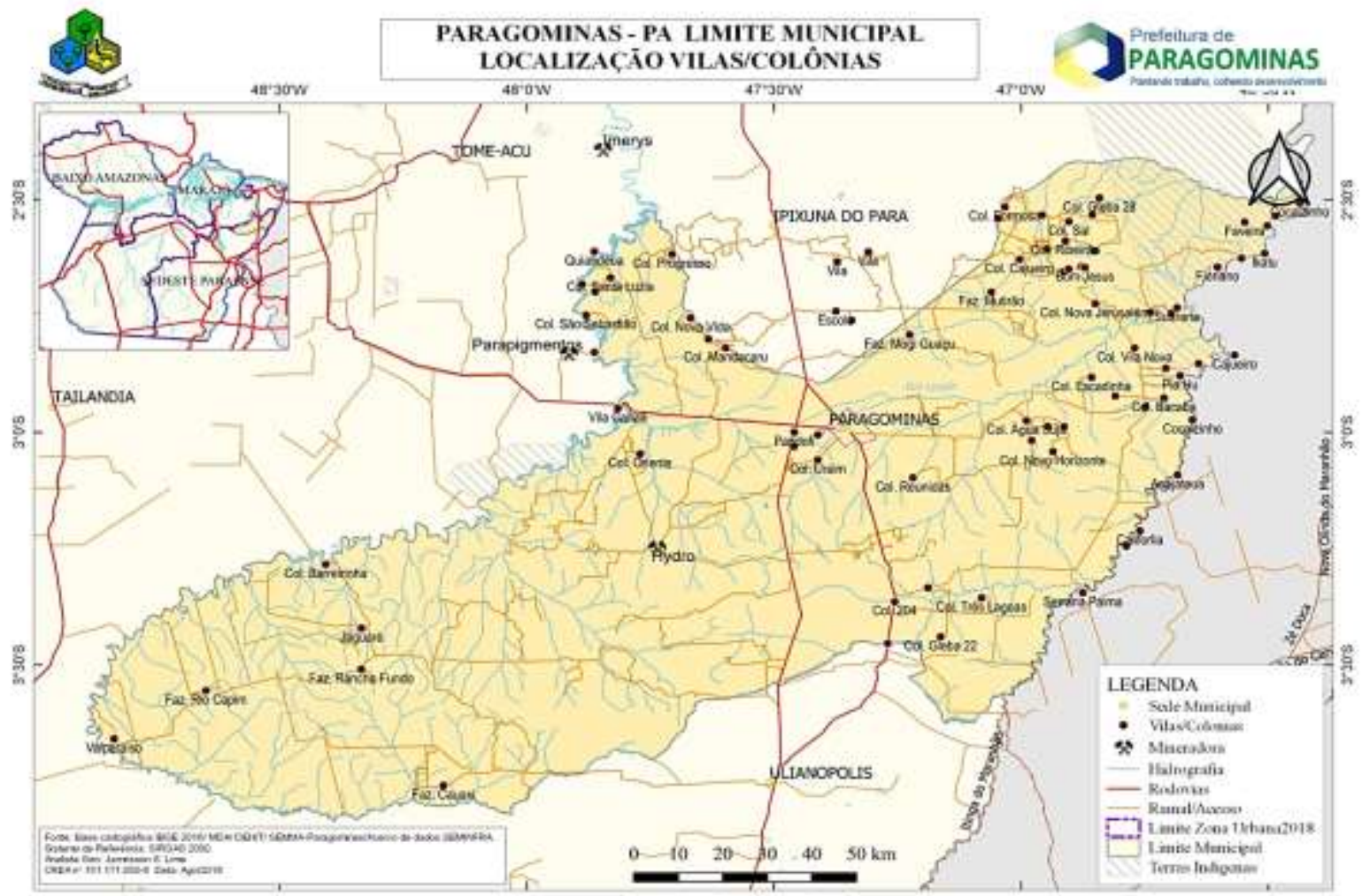

Fonte: Secretaria Municipal de Agricultura de Paragominas (2019)

\subsubsection{Elaboração do Diagnóstico}

Foi elaborado um roteiro semiestruturado geral com questões que norteavam as entrevistas, dando um caráter de "conversa" informal, de acordo com Verdejo (2003). Todos os entrevistados responderam o mesmo questionário, contendo todos os eixos temáticos nas diferentes linhas de pesquisa.

Os dados usados no presente trabalho, após extração das questões relacionadas aos SAF's identificados no município, foram: caracterização das propriedades, presença ou ausência de SAF, espécies componentes do sistema, produção, área, organização social, aspectos econômicos, políticas públicas, questões fundiárias, produção e comercialização e vertentes ambientais, todos analisados qualitativamente. 
Para a sistematização das informações obtidas, foi elaborado um programa no Microsoft Excel 2010 que fosse capaz de tabular os dados e assim gerar as tabelas e gráficos correspondentes de cada vertente estudada.

\section{RESULTADOS E DISCUSSÃO}

\subsection{Caracterização dos Sistemas Agroflorestais em Paragominas}

A principal linha da pesquisa analisada no diagnóstico foi a presença de sistemas agroflorestais por comunidades no município de Paragominas, onde se percebeu que em 21 comunidades, do total de 32 pesquisadas, há pelo menos um SAF implantado. Assim, a comunidade que mais se destacou foi a Faixa 3 na CAIP, com sete unidades, seguida por Cachoeira e Colônia do Uraim, com cinco arranjos cada, e por Nazaré e Oriente, com quatro (Gráfico 1). Observou-se que, dentro dos diversos arranjos produtivos trabalhados pelos agricultores pesquisados, foi encontrado $18 \%$ de propriedades com SAF implantado.

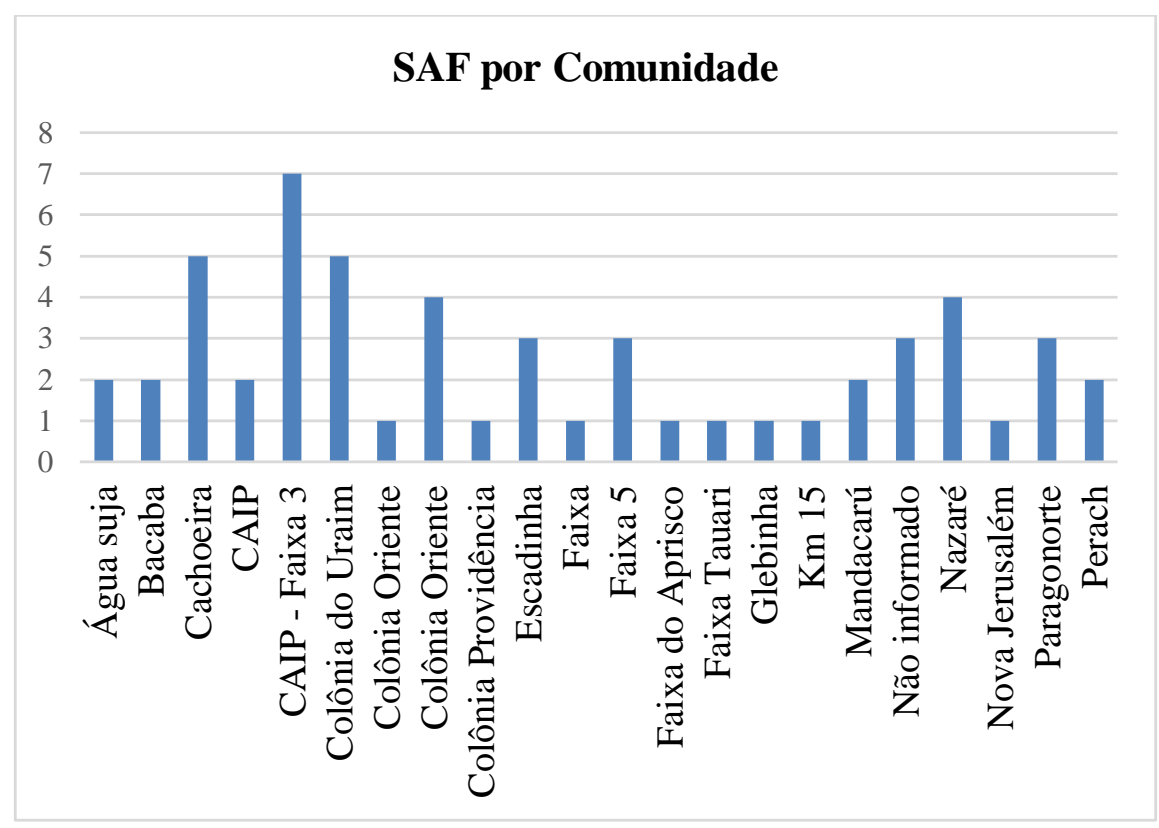

Gráfico 1: Quantidade de sistemas agroflorestais em comunidades rurais do município de Paragominas-Pa.

As áreas das propriedades pesquisadas variaram de 1 a 175 hectares, sendo que a maioria (41\%) tinha de 21 a 50 ha, caracterizando pequenas propriedades, seguida de $37 \%$ que correspondia a lotes de até 10 hectares, 13\% acima de 50 hectares e $9 \%$ entre 11 e 20 hectares. A legislação vigente reconhece que, para se enquadrar como agricultor familiar, a família pode ser proprietária de até quatro módulos fiscais, sendo que, no município de Paragominas, essa medida equivale a 220 hectares.

A presença de sistemas agroflorestais nessas regiões pode ser compreendida em parte pela ação da assistência técnica, exercida por órgãos governamentais como: Empresa de Assistência 
Técnica e Extensão Rural - EMATER-PA e Secretaria Municipal de Agricultura de Paragominas, (ambas atuando em todo o território do município de Paragominas), Instituto de Desenvolvimento Florestal e da Biodiversidade do Estado do Pará - Ideflor-Bio, (com atuação principalmente na região do Rio Capim), Centro de Cooperação Internacional em Pesquisa Agronômica para o desenvolvimento - CIRAD, em parceria com a Empresa Brasileira de Pesquisa Agropecuária EMBRAPA, com projetos na região do Assentamento Luís Inácio, conhecido como Paragonorte, entre outros, iniciados em 2013 como política pública de redução de áreas desmatadas no Pará.

Essas atuações levaram em consideração a aptidão agrícola local, fator de extrema importância, uma vez que o sistema de manejo a ser empregado em um dado local depende fundamentalmente das condições de solo e clima dessa área e da necessidade de segurança alimentar aliada a geração de renda. Outro fator a ser considerado que ajuda a justificar a ausência de sistemas agroflorestais em outras comunidades é a dinâmica ocupacional de boa parte das outras localidades, que é influenciada pela cultura passada de geração em geração, como a criação de gado e cultivo de pimenta do reino, mandioca entre outros.

Silva et al. (2018), em estudo sobre os ribeinhos e os sistemas agroflorestais agroecológicos na ilha Mamangal, Igarapé-Miri- Pará, encontrou um percentual de $28 \%$ de famílias que trabalham com sistemas agroflorestais, mostrando uma diferença modesta do percentual desse sistema de produção quando comparado à porcentagem encontrada em Paragominas. Isso mostra que o município ainda tem que avançar muito na adoção de SAF's como meio de produção da agricultura familiar para fortalecer a biodiversidade e a preservação ambiental.

Em estudo sobre dez anos de pesquisa em sistemas agroflorestais no Estado do Mato Grosso do Sul, Nicodemo \& Melotto (2013) encontraram diferentes quantidades de SAF's em diversos municípios daquele estado, com destaque para Corumbá, com 387; Niogue, com 82; Amambai, com 67; e Aparecida do Tabuado, com 65, mostrando uma disparidade muito grande entre a distribuição desse arranjo produtivo.

Nesse caso, segundo os mesmos autores, todos os municípios mencionados como maiores detentores de área com SAFs são de tradição muito forte na pecuária. Logo, os autores inferiram que ou a atividade florestal foi inserida na criação de animais ou o gado passou a ser criado tanto em cultivos florestais plantados como junto à floresta nativa, que, ao invés de ser derrubada, foi somente raleada - na maioria dos casos, realidade que pode ser utilizada no município de Paragominas.

\subsection{Produção dos SAFs, comercialização e acesso a crédito}

Os agricultores familiares informaram a existência de 34 culturas prioritárias em sistemas agroflorestais nas comunidades participantes (Tabela 1), dentre as quais se destacam as fruteiras como açaí (Euterpe oleracea Mart.), perfazendo 30\%; cupuaçu (Theobroma grandiflorum (Willd. ex Spreng.) K. Schum.), totalizando 22\%; abacaxi (Ananas comosus (L.) Merril), com $20 \%$. As demais culturas são melão (Cucumis melo L.); cana-de-açúcar (Saccharum officinarum L.) e melancia (Citrullus lanatus (Thunb.) Matsum. \& Nakai.). Os principais componentes florestais citados foram: castanha do Pará (Bertholletia excelsa Bonpl.), com 100\%; mogno (Swietenia macrophylla King.), com 67\%; e andiroba (Carapa guianensis Aubl.), ipê (Handroanthus albus (Chamiso) Mattos) e paricá (Schizolobium amazonicum Huber ex. (Ducke)), com 50\% de participação nos arranjos. 
Tabela 1: Relação das culturas plantadas em sistemas agroflorestais e seus percentuais em relação ao total dos sistemas de produção nas comunidades rurais do município de Paragominas-Pa.

\begin{tabular}{|c|c|c|c|}
\hline Nome popular & Nome científico & $\begin{array}{l}\text { Produção em } \\
\text { SAF frente ao } \\
\text { total produzido }\end{array}$ & $\begin{array}{l}\text { Percentual da } \\
\text { cultura em } \\
\text { relação às } \\
\text { áreas com SAF. }\end{array}$ \\
\hline Abacaxi & Ananas comosus (L.) Merril & $20 \%$ & $12,5 \%$ \\
\hline Abóbora & Curcubita spp & $6 \%$ & $1,8 \%$ \\
\hline Açaí & Euterpe oleracea Mart. & $30 \%$ & $27 \%$ \\
\hline Alface & Lactuca sativa $\mathrm{L}$. & $3 \%$ & $5,3 \%$ \\
\hline Andiroba & Carapa guianensis Aubl. & $50 \%$ & $8,9 \%$ \\
\hline $\begin{array}{c}\text { Arroz } \\
\text { Banana } \\
\text { Batata doce }\end{array}$ & $\begin{array}{c}\text { Oriza sativa } \mathrm{L} . \\
\text { Musa paradisíaca } \mathrm{L} . \\
\text { Ipomoea batatas (L.) Lam. }\end{array}$ & $\begin{array}{l}19 \% \\
14 \% \\
15 \%\end{array}$ & $\begin{array}{c}12,5 \% \\
16 \% \\
7,1 \%\end{array}$ \\
\hline $\begin{array}{c}\text { Caju } \\
\text { Cana de açúcar } \\
\text { Castanha do Pará }\end{array}$ & $\begin{array}{l}\text { Anacardium ocidentales L. } \\
\text { Saccharum officinarum L. } \\
\text { Bertholletia excelsa Bonpl. }\end{array}$ & $\begin{array}{c}16 \% \\
22 \% \\
100 \%\end{array}$ & $\begin{array}{l}30,3 \% \\
3,6 \% \\
3,6 \%\end{array}$ \\
\hline $\begin{array}{l}\text { Coentro } \\
\text { Couve } \\
\text { Coco }\end{array}$ & $\begin{array}{c}\text { Coriandrum sativum } \mathrm{L} . \\
\text { Brassica oleracea } \mathrm{L} . \\
\text { Cocos nucifera } \mathrm{L} .\end{array}$ & $\begin{array}{c}3 \% \\
14 \%\end{array}$ & $\begin{array}{l}1,8 \% \\
3,6 \% \\
7,4 \%\end{array}$ \\
\hline $\begin{array}{l}\text { Cupuaçu } \\
\text { Feijão caupi }\end{array}$ & $\begin{array}{c}\text { Theobroma grandiflorum (Willd. ex } \\
\text { Spreng.) K. Schum. } \\
\text { Vigna unguiculta (L.) Walp }\end{array}$ & $22 \%$ & $\begin{array}{l}14,3 \% \\
23,2 \%\end{array}$ \\
\hline Goiaba & Pisidium guajava $\mathrm{L}$. & $9 \%$ & $3,6 \%$ \\
\hline Ipê & Handroanthus albus (Chamiso) Mattos & $50 \%$ & $5,3 \%$ \\
\hline $\begin{array}{l}\text { Laranja } \\
\text { Limão } \\
\text { Mandioca } \\
\text { Mamão } \\
\text { Maracujá } \\
\text { Maxixe }\end{array}$ & $\begin{array}{c}\text { Citros cinensis (L.) Osbeck. } \\
\text { Citros limon (L.) Burm. } \\
\text { Manihot esculenta Crantz } \\
\text { Caripa papaya L. } \\
\text { Passiflora edulis Sims } \\
\text { Cucumis anguria } \mathrm{L} .\end{array}$ & $\begin{array}{c}5 \% \\
12 \% \\
9 \% \\
10 \% \\
17 \% \\
6 \%\end{array}$ & $\begin{array}{l}5,3 \% \\
8,9 \% \\
30 \% \\
5,3 \% \\
1,8 \% \\
1,8 \%\end{array}$ \\
\hline $\begin{array}{l}\text { Melancia } \\
\text { Melão } \\
\text { Milho } \\
\text { Mogno } \\
\text { Paricá }\end{array}$ & $\begin{array}{l}\text { Citrullus lanatus (Thunb.) Matsum. \& } \\
\text { Nakai. } \\
\text { Cucumis melo L. } \\
\text { Zea mays L. } \\
\text { Swietenia macrophylla King. } \\
\text { Schizolobium amazonicum Huber ex. } \\
\text { (Ducke) }\end{array}$ & $\begin{array}{l}20 \% \\
33 \% \\
15 \% \\
67 \% \\
50 \%\end{array}$ & $\begin{array}{c}3,6 \% \\
1,8 \% \\
26,8 \% \\
1,8 \% \\
1,8 \%\end{array}$ \\
\hline $\begin{array}{l}\text { Pepino } \\
\text { Pimenta do reino } \\
\text { Pimentinha } \\
\text { Quiabo } \\
\text { Urucum }\end{array}$ & $\begin{array}{c}\text { Cucumis sativos } \mathrm{L} . \\
\text { Piper nigrum } \mathrm{L} . \\
\text { Capiscum spp. } \\
\text { Abelmoschus esculentus (L.) Moench. } \\
\text { Bixa orellana L. }\end{array}$ & $\begin{array}{c}12 \% \\
5 \% \\
7 \% \\
6 \% \\
14 \% \\
\end{array}$ & $\begin{array}{l}5,3 \% \\
5,3 \% \\
1,8 \% \\
1,8 \% \\
8,9 \%\end{array}$ \\
\hline
\end{tabular}

Há de se ressaltar que existem outras culturas com múltiplas funções relatadas nas conversas, porém não foram quantificadas. Um exemplo é o caso do ingá (Inga edulis L.), que é uma espécie adubadora com a função tanto de fixar nitrogênio quanto de ciclagem de nutrientes, além de fornecer fruto comestível. Outras espécies também citadas foram a fava (Phaseolus lunatus L.) e o feijão guandu (Cajanus cajan (L. Millsp.)), demostrando que, em geral, os sistemas 
agroflorestais encontrados apresentam-se bem diversificados e com importantes serviços ambientais.

É notável que existe uma articulação da diversidade biológica com a diversidade cultural que, segundo Coelho-de-Sousa (2018), pode ser entendida como a relação entre os sistemas tradicionais de produção e o uso e manejo da diversidade biológica, junto com o conhecimento e a cultura das populações tradicionais e agricultores familiares. Nesse sentido, várias espécies cumprem esse papel de serem produzidas com uma finalidade diferente de apenas comercialização, cumprindo uma função cultural no processo de lidar com a terra.

Na Tabela 1 ainda foi possível verificar o percentual de cada espécie em relação ao total de propriedades com SAF's, sendo o caju (Anacardium ocidentales L.), feijão-caupi (Vigna unguiculta (L.) Walp) e o milho (Zea mays L.) as culturas com maiores percentuais. A forte participação do caju pode ser justificada, em parte pela sua resistência à seca, uma vez que na maioria expressiva dos locais existe um período seco bem definido que vai de julho a novembro. Já o feijão-caupi e o milho se justificam pela questão da subsistência e, no caso da leguminosa, como fonte fixadora de nitrogênio.

Medeiros (2018), em seu trabalho sobre aptidão climática da cultura do caju na bacia hidrográfica do Rio Ipojuca, destaca que, para que haja um potencial produtivo em culturas frutíferas, é fundamental observar a adaptação da planta às condições edafoclimáticas. $O$ autor conclui seus estudos mostrando que é possível o uso da cultura do cajueiro em locais com certa limitação de chuvas, uma vez que o mesmo apresenta resistência ao estresse hídrico.

Quando os entrevistados foram arguidos sobre o uso de agrotóxicos no controle de pragas e/ou doenças e/ou de plantas espontâneas em suas propriedades, $45 \%$ disseram que usam e $23 \%$ não usam. Os demais agricultores (32\%) relataram que usam outros métodos de controle, incluindo o biológico e mecânico.

Esses dados, apesar de serem preocupantes por conta do alto percentual de uso de produtos químicos, podem ser atenuados, uma vez que, quando se analisa a frequência de uso desses produtos, percebe-se que apenas $8 \%$ dos produtores disseram usar esse tipo de controle sempre, contra $59 \%$ de uso eventual e $33 \%$ que dificilmente usam.

Em estudo sobre o uso de agrotóxicos por agricultores familiares de Maragogi/AL, Cavalcante, et al. (2015) constataram que $60 \%$ dos entrevistados relataram aplicar agrotóxicos pelo menos uma vez ao mês e com agravante de não ser de acordo com uma recomendação devida. Na verdade, essa tem sido a realidade do uso de agrotóxicos por pequenos produtores pelo menos no norte do País, uma vez que não disponibilizam de assistência técnica adequada.

Dentre os produtos químicos utilizados pelos proprietários, se destacaram (de forma cumulativa) os herbicidas, citados por $32 \%$ dos entrevistados; inseticidas, com $23 \%$ de frequência; fungicidas, com $4 \%$ de participação; e $1 \%$ de outros produtos. Ressalta-se que $55 \%$ dos produtores não faz uso de nenhum tipo de tratamento químico.

Os resultados mostraram que $48 \%$ dos produtores fizeram algum tipo de beneficiamento em pelo menos um de seus produtos, contra $52 \%$ que não tinham nenhum tipo de benfeitoria no processo de produção. Isso nos mostra que, de certa forma, há um grau considerável de agregação de valor em algumas mercadorias oriundas dos sistemas agroflorestais, porém, quando se observa 
a quantidade de produtos que são trabalhados dessa maneira, fica evidente a necessidade de maiores investimentos nessa área, pois há um potencial muito grande para ser explorado.

Dentre os produtos citados como beneficiados, se destacam a farinha de mandioca, com $66 \%$; polpa de fruta, com 26\%; e $8 \%$ de outros produtos. Silva et al. (2018) aponta que a farinha de mandioca em geral é produzida em "casas de farinha", que, na maioria das vezes, apresentam problemas de adequação às exigências da legislação devido a problemas de precariedade no processamento e nas condições higiênico-sanitárias. Esse fato evidencia ainda mais a necessidade de políticas públicas para a facilitar a industrialização dos produtos oriundos da agricultura familiar.

A propósito do destino prioritário da produção dos produtos dos sistemas agroflorestais, foi observado que $16 \%$ foram entregues a atravessadores, $14 \%$ seguiu para consumo próprio, $31 \%$ foram destinados a feiras e supermercados, $6 \%$ para a merenda escolar e $33 \%$ são comercializados na própria comunidade.

Estes resultados ressaltam a importância dos produtos dos SAF's na alimentação dos agricultores familiares com relação ao que é produzido, caracterizando que esses sistemas são capazes de suprir a necessidade alimentar das famílias e favorecem a diversificação dentro do arranjo produtivo.

Entretanto, há de se considerar as dificuldades na comercialização da produção, pois os entrevistados relataram que $14 \%$ dos produtos são vendidos para atravessadores. Essa prática é corriqueira na agricultura familiar, uma vez que é o meio mais prático e rápido de comercialização quando o agricultor não consegue acesso aos mercados. Outro fator a ser considerado é a participação em feiras, que se mostrou com percentual considerável.

Ainda como dificuldades prioritárias enfrentadas na comercialização, os produtores apontam: falta de comprador fixo, 35\%; estradas ruins, 24\%; falta de transporte dos produtos, 21\%; maior distância do mercado consumidor, $9 \%$; e outros fatores, $6 \%$.

A falta de comprador fixo pode estar relacionada à sazonalidade da produção dos sistemas agroflorestais, que ganha em diversificação, mas muitas vezes perde em quantidades suficientes para atender a um determinado mercado.

Ao se analisar as dificuldades enfrentadas no sistema de produção, foi aferido que $32 \%$ dos entrevistados apresentaram a falta de recursos financeiros; $30 \%$ apontaram a falta de apoio governamental; 19\%, falta de assistência técnica; $10 \%$, problemas na comercialização; e $9 \%$, outros, como falta de mão de obra.

A falta de recursos financeiros, via de regra, está atrelada à falta de acesso às políticas públicas de financiamento e incentivo da agricultura familiar, como é o caso do Programa Nacional de Fortalecimento da Agricultura Familiar - Pronaf, Fundo Constitucional de Financiamento do Norte - FNO, Programa Nacional de Alimentação Escolar - PNAE, Programa de Aquisição de Alimentos da Agricultura Familiar - PAA, entre outros, fato que acaba entrando na estatística da falta de apoio governamental.

Quando questionados sobre as soluções para melhorar as dificuldades enfrentadas, os resultados mostraram que $40 \%$ dos pesquisados acreditam que a situação pode mudar com melhorias nas estradas; $27 \%$ afirmam que a mudança viria através do engajamento em uma associação ou cooperativa; $26 \%$, por outro lado, acreditam que a aquisição de transporte resolveria o problema e $7 \%$ citaram outras situações. 
Ao serem perguntados sobre o acesso a crédito, apenas $29 \%$ dos produtores responderam que já tiveram acesso a algum tipo de financiamento, ao contrário de $61 \%$ que nunca foram contemplados com crédito financeiro. As fontes de crédito listadas pelos agricultores seguem a ordem de: 56\% Pronaf A; 12,5\% FNO; 12,5\% Microcrédito; e 19\% outras fontes. Juntos, Pronaf e FNO somam 68,5\% dos programas de incentivo financeiro à Agricultura Familiar.

Apesar da alta representatividade dos dois programas governamentais citados acima, Santana (2013) aponta para uma baixa eficiência do FNO e do Pronaf na captação de recursos direcionados à pequena produção e aos extrativistas, em função de diversas dificuldades, entre elas a falta de garantias para acesso a um montante adequado de crédito, para que o produto das atividades financiadas possam mover os efeitos multiplicadores de produto, renda e emprego.

\section{3 Caracterização socioeconômica e organização social}

Quanto ao gênero dos agricultores responsáveis pelos SAF's, $60 \%$ são do sexo masculino e $40 \%$ do sexo feminino. A média da idade dos entrevistados foi de 48 anos, sendo que 34,55\% encontram-se na faixa etária entre 51 a 60 anos (Gráfico 2a). Camargo (2017), em estudo sobre sistemas agroflorestais biodiversos no Mato Grosso do Sul, encontrou resultados com variações significativas, mostrando $72 \%$ de participação do sexo masculino e $28 \%$ do sexo feminino, com média de idade dos entrevistados de 56 anos, perfazendo um total de $61,2 \%$ de indivíduos na faixa etária entre 61 a 70 anos.

No que se refere à escolaridade, a maioria dos entrevistados (58\%) possuía apenas o ensino fundamental incompleto (1ㅇa a 9o ano), 15\% concluíram o ensino fundamental, $9 \%$ não concluíram a educação de nível médio, $7 \%$ responderam ser analfabetos e $5 \%$ conseguiram terminar o ensino médio. Os restantes (6\%) estão distribuídos em alfabetizados, nível superior completo e outros que não informaram (Gráfico 2B). Esse quadro demonstra que grande parte dos agricultores tem baixo nível de formação, o que, segundo Camargo, et al. (2019), pode prejudicar o acesso a informações e novas tecnologias, assim como aumentar as dificuldades na gestão da propriedade na hora da comercialização e no controle de custos e receitas, inviabilizando o empreendimento.
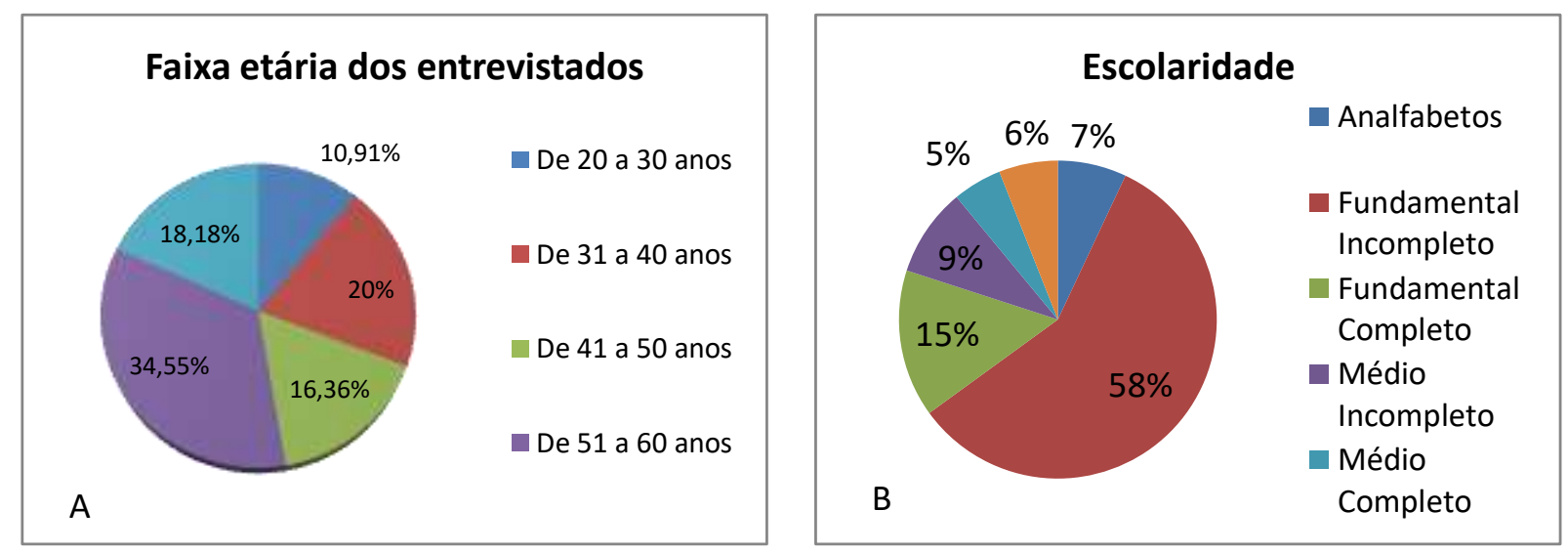

Gráfico 2: a) Faixa etária; b) - escolaridade de agricultores com SAF no município de Paragominas - Pa. 
Quanto à participação dos entrevistados em alguma organização social, foi verificado que $67 \%$ faziam parte de alguma associação, cooperativa ou do sindicato dos trabalhadores e trabalhadoras rurais de Paragominas. É importante ressaltar que a maioria dos produtores estão organizados em algum tipo de entidade representativa, porém, segundo dados da Secretaria de Agricultura Municipal de Paragominas, das 52 associações de moradores e/ou pequenos produtores rurais do município, apenas 4 estão em dia com suas obrigações fiscais e funcionando de acordo com o prescrito na lei. Essa informação causa preocupação, pois essas entidades na prática não estão desenvolvendo seu papel de forma eficiente devido à falta de regularização (SECRETARIA MUNICIPAL DE AGRICULTURA DE PARAGOMINAS, 2019).

De acordo com Sangalli, et al. (2015), uma associação pode melhorar a atuação do pequeno agricultor no mercado e assim gerar um melhor rendimento econômico, mostrando que o associativismo é uma ferramenta extremamente importante para a melhoria da qualidade de vida no campo e o combate ao êxodo rural. Logo, faz-se necessário uma melhor estruturação dessas entidades associativas para que possam melhor contribuir com o desenvolvimento das comunidades das quais fazem parte.

Quanto à renda familiar mensal, percebe-se que a maioria (75\%) declarou receber até um salário mínimo, seguido de $23 \%$ que recebem de 1 a 3 salários e os outros $2 \%$ que obtêm um ganho entre 3 a 5 salários (Gráfico 3). Isso nos mostra que a renda obtida desses sistemas de produção ainda é muito incipiente, ora porque a produção é usada para alimentação familiar, ora por problemas de comercialização e beneficiamento, já relatados anteriormente.

Camargo et al. (2019), encontraram um percentual de $66,7 \%$ de produtores em sistemas agroflorestais com renda de até um salário mínimo e somente $5,6 \%$ com rendimento superior a três salários mínimos. Essa realidade aponta para a necessidade de um maior planejamento das atividades de produção, maior diversificação e aplicação de tecnologias que possibilitem aumento de produtividade, melhorando a comercialização dos produtos. Ainda, aponta-se a busca pela verticalização da produção, uma vez que a maioria dos produtos, via de regra, são vendidos na sua forma "in natura". Outra estratégia que pode ajudar a resolver essa questão é a eliminação de atravessadores, que acabam abarcando a maior parte dos rendimentos da produção, uma vez que compram barato e se preocupam basicamente com a logística de compra e comercialização.

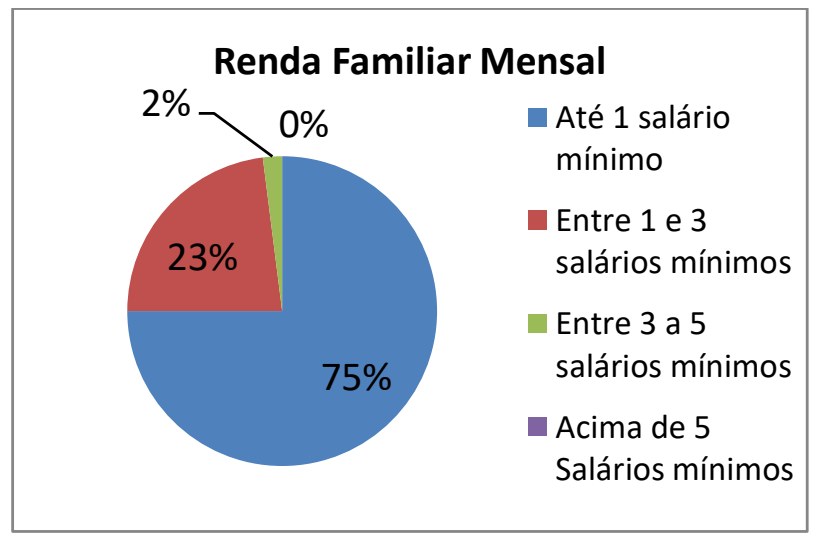

Gráfico 3: Renda mensal familiar de agricultores com SAF no município de Paragominas-Pa. 


\subsection{Uso da terra em propriedades com SAFs}

Quanto à posse da terra, a situação parece ser semelhante ao que é encontrado no Estado do Pará. Os dados revelam que $37 \%$ dos entrevistados declararam ser posseiros, índice que sobe para $39 \%$ se considerar os $2 \%$ que compraram de posseiros (incluídos em outros) e, portanto, se tornaram ocupantes irregulares também. Ainda, $26 \%$ são assentados, $24 \%$ titulares e os outros $11 \%$ estão em situações diversas, como arrendatários, por exemplo.

Essas informações demostram que ainda está longe de alcançar um patamar digno de regularização fundiária no Estado e consequentemente em Paragominas, havendo a necessidade iminente de maior esforço por parte dos órgãos competentes de sanar essa situação.

Outro fator analisado de forma não cumulativa foram os documentos da terra: $45 \%$ dos entrevistados disseram não possuir nenhum documento; $33 \%$ possuem o Cadastro Ambiental Rural - CAR e, em alguns casos, outros documentos; $16 \%$ portam a Declaração de Aptidão ao Pronaf - DAP, dos quais alguns possuem outros documentos; apenas 8\% têm título definitivo e 7\% estão dentro do Programa Terra Legal do Governo do Estado. Infelizmente há um percentual muito alto de agricultores em situação irregular no campo, reflexo das várias ocupações ocorridas em diversas localidades do município, fato que é comum por todo o país.

Os resultados nos mostram que infelizmente há um percentual muito alto de agricultores em situação irregular no campo, reflexo das várias ocupações ocorridas em diversas localidades do município, fato que é comum por todo o país.

\section{CONCLUSÃO}

No decorrer do trabalho, foi verificado que há presença de áreas com SAF's no município, informação importante para o planejamento de ações estratégicas de ampliação de sistemas diversificados de cultivos e geração de renda nas propriedades. Em sua maioria, são pequenas áreas, entre 21 e 50 hectares, sem regularização fundiária e trabalhando na informalidade. A grande diversificação de culturas nos SAF contribui para distribuição de renda ao longo do ano e segurança alimentar dos agricultores familiares desse município.

No que diz respeito ao nível de instrução dos entrevistados, a maioria possui apenas o ensino fundamental incompleto, o que pode ser um entrave para o acesso às novas tecnologias $e$ formalização da propriedade. Entretanto, como a maioria participa de alguma organização social, pode ter acesso a créditos com maior facilidade, além de buscar soluções para os problemas na comercialização, como a falta de comprador fixo, estradas ruins e falta de verticalização da produção.

Porém, apesar das dificuldades, os produtores e seus respectivos SAF's estudados apresentam inúmeros resultados positivos, principalmente na esfera social e ambiental, tais quais: a maioria já participou de algum tipo de capacitação técnica; a maior parte da produção é comercializada em feiras e na comunidade local, o que aproxima produtor e consumidor final, diminui custos e consequentemente o preço do produto, gerando ganhos para ambos os lados; baixo índice de frequência de uso de produtos químicos; e diversificação da produção, o que traz renda durante o ano todo para as famílias envolvidas. 
O presente trabalho pôde trazer clareza à situação dos sistemas agroflorestais do município, uma vez que essa área foi pouco estudada e debatida ao longo dos anos em Paragominas, apesar de sua extrema importância como fator de desenvolvimento rural sustentável. Logo, há de ressaltar a relevância do estudo para que se possa traçar novas alternativas, tanto políticas como técnicas, por parte do poder público, a fim de que essa atividade seja potencializada no âmbito municipal.

\section{REFERÊNCIAS BIBLIOGRÁFICAS}

ABDO, M. T. V. N.; VALERI, S. V.; MARTINS, A. L. M. Sistemas Agroflorestais e Agricultura Familiar: uma parceria interessante. Revista Tecnologia \& Inovação Agropecuária. Dezembro de 2008. Pg 49-58.

AZEVEDO, A. et al. Panorama sobre o desmatamento na Amazônia em 2016. IPAM Amazônia. Belém. $2016 . \quad$ Disponível em: http://www.observatorioflorestal.org.br/sites/default/files/panorama-desmatamentoamazonia-2016.pdf. Acessado em 16 de fevereiro de 2018.

CAMARGO et al. Sistemas agroflorestais biodiversos: uma análise da sustentabilidade socioeconômica e ambiental. Revista Brasileira de Gestão e Desenvolvimento Regional, v. 15, n. 1, p. 34-46, jan-abr/2019, Taubaté, SP, Brasil

CAMARGO, G. M. de. Sistemas agroflorestais biodiversos: uma análise da sustentabilidade socioeconômica e ambiental. Dissertação (Mestrado em Agronegócios) - Universidade Federal da Grande Dourados, Dourados. 2017. 130 p.

CARVALHO, F. S. et al. Dinâmica de uso da terra, no setor agropecuário, em Paragominas - PA. Rev. Agroecossistemas, v. 9, n. 2, p. $148-163,2017$.

CAVALCANTE, M.; SANTOS, F. X. dos; PEREIRA, D. A.; BARBOSA, T. J. de A.; SILVA NETO, J. V. da. Diagnóstico do uso de agrotóxicos por agricultores familiares de Maragogi/AL. Cadernos de Agroecologia - ISSN 2236-7934 - Vol. 10, № 3 de 2015.

COELHO-DE-SOUZA, Gabriela et al. Sociobiodiversidade, soberania e segurança alimentar e nutricional: uma análise da governança do butiá [resumo expandido]. Anais [do] Encontro Internacional da Rota dos Butiazais (2.: 2018: Pelotas, RS), 2018.

IBGE. Estimativa da população residente no Brasil e unidades da federação com data de referência em 10 de julho de 2016.2 Disponível em: ftp://ftp.ibge.gov.br/Estimativas de Populacao/Estimativas 2016/estimativa dou 201620 160913.pdf. Acessado em: 22 de Agosto de 2017.

INPE. PROJETO PRODES: Monitoramento da Floresta Amazônica Brasileira por Satélite. http://www.obt.inpe.br/prodes/. INPE, 2009.

INSTITUTO NACIONAL DE PESQUISAS ESPACIAIS (INPE). Desmatamento por municípios. Projeto PRODES. São José dos Campos, São Paulo: Instituto Nacional de Pesquisas Espaciais, 2013. 
MEDEIROS, R. M. Aptidão climática da cultura do caju na bacia hidrográfica do Rio Ipojuca. Anais da Academia Pernambucana de Ciência Agronômica, v. 15, n. 2, p. 125-138, 2018.

MICCOLIS A. et al. Restauração Ecológica com Sistemas Agroflorestais: como conciliar conservação com produção. Opções para o cerrado e caatinga. Brasília: Instituto Sociedade, População e Natureza - ISNP/ Centro Internacional de Pesquisa Agroflorestal - ICRAF, 2016. 266p.

NICODEMO, M. L. F; MELOTTO, A. M. 10 Anos de Pesquisa em Sistemas Agroflorestais em Mato Grosso do Sul. Embrapa. Campo Grande - MS. 2013. Disponível em: https://www.alice.cnptia.embrapa.br/alice/bitstream/doc/960942/1/PROCl2013.00045.pdf Acessado em 21 de Junho de 2019.

OLIVEIRA, J. E. Monitoramento participativo de sistemas agroflorestais nos assentamentos do município de Iperó - SP. Dissertação (Mestrado) UFSCar, 2016. 134 p.

SANGALLI, A. R. et al. Associativismo na Agricultura Familiar: contribuições para o estudo do desenvolvimento no Assentamento rural Lagoa Grande, em Dourados (MS), Brasil. Rev. Organizações Rurais \& Agroindustriais, Lavras, v. 17, n. 2, p. 225-238, 2015.

SANTANA, A. C. Efeitos do FNO no desenvolvimento socioeconômico da Região Norte: análise de eficácia. Belém: Banco da Amazônia, 2013. 228p.

SECRETARIA MUNICIPAL DE AGRICULTURA DE PARAGOMINAS. Levantamento Social das Comunidades Rurais de Paragominas. Documentos Internos. Paragominas. 2019.

SILVA, A. et al. Os ribeinhos e os Sistemas agroflorestais agroecológicos na ilha Mamangal, IgarapéMiri-Pará. Cadernos de Agroecologia, v. 13, n. 1, 2018.

SILVA, R. F. da; SISSI, S. A. de A; MOURA, A. A.; SILVA, A M. Agricultura familiar: a produção e o manejo de farinha de mandioca na comunidade Kalunga Vão de Almas e suas contribuições para a educação do campo: Case report. J Business Techn. 2018.

VERDEJO, M. E. Diagnóstico rural participativo: guia prático. Centro Cultural Poveda, Proyecto Comunicación y Didáctica, 2003. 